\title{
Distinct Contributions of Median Raphe Nucleus to Contextual Fear Conditioning and Fear-Potentiated Startle
}

\author{
R.C.B. Silva, A.P.M. Cruz , ${ }^{1}$ V. Avanzi, J. Landeira-Fernandez ${ }^{2}$ and M.L. Brandão \\ Laboratório de Psicobiologia, FFCLRP, Campus USP, Av. Bandeirantes 3900, Ribeirão \\ Preto; ${ }^{1}$ Laboratório de Psicobiologia, Departamento de Processos Psicológicos Básicos, IP- \\ Universidade de Brasília, Campus Darcy Ribeiro, 70910-900, Brasília, ${ }^{2}$ Departamento de \\ Psicologia, Pontificia Universidade Católica do, Rio de Janeiro, \\ Rua Marques de São Vicente 225, 22453-900, Rio de Janeiro; Brazil
}

\begin{abstract}
Ascending 5-HT projections from the median raphe nucleus (MRN), probably to the hippocampus, are implicated in the acquisition of contextual fear (background stimuli), as assessed by freezing behavior. Foreground cues like light, used as a conditioned stimulus (CS) in classical fear conditioning, also cause freezing through thalamic transmission to the amygdala. As the MRN projects to the hippocampus and amygdala, the role of this raphe nucleus in fear conditioning to explicit cues remains to be explained. Here we analyzed the behavior of rats with MRN electrolytic lesions in a contextual conditioning situation and in a fearpotentiated startle procedure. The animals received MRN electrolytic lesions either before or on the day after two consecutive training sessions in which they were submitted to 10 conditioning trials, each in an experimental chamber (same context) where they received foot-shocks $(0.6 \mathrm{~mA}, 1 \mathrm{sec})$ paired to a 4-sec light CS. Seven to ten days later, the animals were submitted to testing sessions for assessing conditioned fear when they were placed for five
\end{abstract}

Reprint requests to: Prof. M.L. Brandão, Laboratório de Psicobiologia, FFCLRP, Campus USP, Av. Bandeirantes 3900, 14049-901, Ribeirão Preto, SP, Brazil; mbrandao@usp.br shocks, and the duration of contextual freezing was recorded. The animals were then submitted to a fear-potentiated startle in response to a 4sec light-CS, followed by white noise $(100 \mathrm{~dB}$, $50 \mathrm{~ms}$ ). Control rats (sham) tested in the same context showed more freezing than did rats with pre- or post-training MRN lesions. Startle was clearly potentiated in the presence of lightCS in the sham-lesioned animals. Whereas pretraining lesions reduced both freezing and fearpotentiated startle, the post-training lesions reduced only freezing to context, without changing the fear-potentiated startle. In a second experiment, neurotoxic lesions of the MRN with local injections of $\mathbf{N}$-methyl-Daspartate or the activation of $5-\mathrm{HT}_{1 \mathrm{~A}}$ somatodendritic auto-receptors of the MRN by microinjections of the 5-HT $\mathrm{HA}_{1 \mathrm{~A}}$ receptor agonist 8-hydroxy- 2-(di-n-propylamino)tetralin (8-OHDPAT) before the training sessions also reduced the amount of freezing and the fear-potentiated startle. Freezing is a prominent response of contextual fear conditioning, but does not seem to be crucial for the enhancement of the startle reflex by explicit aversive cues. As fearpotentiated startle may be produced in posttraining lesioned rats that are unable to freeze to fear contextual stimuli, dissociable systems seem to be recruited in each condition. Thus, contextual fear and fear-potentiated startle are 
conveyed by distinct 5-HT-mediated circuits of the MRN.

\section{INTRODUCTION}

Fear conditioning to context can be reliably evaluated by the amount of freezing behavior that animals display when they return to the context in which they received footshock and fear-potentiated startle by the increase of the startle reflex in the presence of an explicit cue paired with shock (Brown et al., 1951; Kim \& Fanselow, 1992; Davis, 1992; Philips \& LeDoux, 1992, 1994; McNish et al., 1997). The hippocampus and amygdala have been the targets of considerable dispute over which structure is mainly involved in the conditioned fear to contextual (background) or explicit (foreground) stimuli (Kim \& Fanselow, 1992; Philips \& LeDoux, 1992, 1994; McNish et al., 1997). Lesions of the amygdala have been shown to block contextual fear conditioning and fear-potentiated startle, whereas lesions of the dorsal hippocampus inhibit only contextual fear conditioning (Kim \& Fanselow, 1992; Philips \& LeDoux, 1992, 1994; McNish et al., 1997).

Median raphe nucleus (MRN) fibers mainly ascend within the medial forebrain bundle in the forebrain, where they project densely to the medial septum and hippocampal formation (Vertes et al., 1999) These neural circuits reportedly encompass the serotonergic behavioral inhibition system (Gray, 1997; Gray \& McNaughton, 2000). The MRN also sends projections to the amygdala (Azmitia \& Segal, 1978; Gray \& McNaughton, 2000). A number of studies have demonstrated that electrolytic or neurotoxic lesions of the median raphe nucleus (MRN) severely disturb the performance of rats in a variety of behavioral tasks. Such a lesion may produce heightened motor activity and increased approach, aberrant hypersexuality, increased feeding behavior, and reduced escape and avoidance responses (Kiser \& Lebovitz, 1975; Srebro \& Lorens, 1975; Geyer et al., 1976; Tye et al., 1977; Hillegaart \& Hjort, 1989; Hillegaart, 1990; Andrade \& Graeff, 2001). Electrical stimulation of this nucleus causes reduced motor output and several autonomic signs, such as micturition and defecation (Graeff \& Silveira-Filho, 1978).

Recently, we showed that electrolytic lesion, chemical lesion with microinjections of NMDA, or inactivation of serotonergic autoreceptors with 8-OH-DPAT of cells of the median raphe nucleus inhibit contextual fear conditioning (Avanzi et al., 1998; Avanzi \& Brandão, 2001). Lesion of this nucleus, however, did not alter the acquisition of the freezing response to a phasic acoustic tone (explicit cue) paired with footshock in the same context (Avanzi \& Brandão, 2001).

The objectives of the present study were twofold:

- to assess the involvement of the median raphe nucleus in two distinct types of conditioned fear, the contextual fear (background stimuli) and the startle reflex potentiated by lightconditioned stimulus (CS) (foreground stimuli); and

- to examine whether serotonergic mechanisms mediate these processes.

The contextual fear was assessed by the amount of freezing the animals displayed when returned to the context in which they were trained. The conditioned fear responses to foreground stimuli were evaluated by the increase in the startle reflex elicited in the presence of an explicit cue that had been paired with shock (fear-potentiated startle). In both procedures, the rats received either sham or electrolytic lesions of the MRN before or after training sessions so that we could evaluate a possible role of the MRN in the acquisition fear conditioning (Experiment I). As the effects of electrolytic lesions could be due to damage of fibers of passage, in Experiment II the electrolytic lesions were replaced by neurotoxic lesions with 
N-methyl-D-aspartate (NMDA), which is selective for cell bodies, or local injections of the selective 5$\mathrm{HT}_{1 \mathrm{~A}}$ receptor agonist 8-OH-DPAT [8-hydroxy-2(di-n-propylamino) tetralin]. Median raphe nucleus injections of 8-OH-DPAT consistently decrease the neuronal impulse flow by the activation of $5-\mathrm{HT}_{1 \mathrm{~A}}$ somatodendritic auto-receptors on raphe cells (Blier \& Montigny, 1987; Hillegaart \& Hjorth 1989; Hillegaart, 1990).

\section{EXPERIMENTAL}

\section{Animals}

Eight-five male Wistar rats, weighing 250 to $280 \mathrm{~g}$ each, were obtained from the animal house of the Campus of Ribeirão Preto of the University of São Paulo. To acclimatize these animals to laboratory conditions, we transferred them to a room adjacent to the test laboratory $48 \mathrm{~h}$ after arrival. They were housed in groups of six per cage, under a 12:12 dark/light cycle (lights on at $0700 \mathrm{~h}$ ) at $23 \pm 1{ }^{\circ} \mathrm{C}$, and given free access to food and water. Following surgery, the animals were housed in groups of 2 for a post-operative recovery period of 7 days. The experiments reported in this paper were performed in compliance with the recommendations of the $\mathrm{SBNeC}$ (Brazilian Society of Neuroscience and Behavior), which are based on the U.S. National Institutes of Health Guide for Care and Use of Laboratory Animals.(NIH Publication No. 85-23, 1985).

\section{Surgery}

The animals were anesthetized with tribromoethanol $(250 \mathrm{mg} / \mathrm{kg}$, i.p.) (Aldrich, USA), which produces a smooth anesthesia in rodents, with a low rate of morbidity and mortality (Papaioannou $\&$ Fox, 1993). The rats were fixed in a stereotaxic frame (David Kopf, USA). A monopolar stainless- steel electrode was stereotaxically implanted in the midbrain, aimed at the median raphe nucleus. The electrode was made of stainless wire, $250 \mu \mathrm{m}$ in diameter, insulated except at the cross-section of the tip. The upper incisor bar was set at $3.3 \mathrm{~mm}$ below the interaural line, so that the skull was vertically lowered using the following coordinates, with bregma serving as the reference for each plane: antero-posterior, $-7.8 \mathrm{~mm}$; dorso-ventral (depth), $9.0 \mathrm{~mm}$; medio-lateral, $2.9 \mathrm{~mm}$ with an angle of $20^{\circ}$ (Paxinos \& Watson, 1997).

Electrolytic lesions were produced by passing anodal current $(2.3 \mathrm{~mA}, 15 \mathrm{~s})$ through the electrode (Albarsh, Brazil). Independent groups of rats underwent identical surgery except that electric current was not delivered (sham). For the experiment with microinjections of NMDA or $8-\mathrm{OH}-$ DPAT into the MRN, each rat was implanted with a stainless-steel guide cannula $(0.6 \mathrm{~mm}$ o.d., 0.4 $\mathrm{mm}$ i.d). The cannula was directed to the MRN at the coordinates described above, except for the depth $(7.0 \mathrm{~mm})$. Each cannula was fixed with polyacrylic cement anchored to the skull with 3 stainless-steel screws and plugged with stainlesssteel stylets. The experiments were started after a 1-wk postoperative delay.

The coordinates used in this study were consistent with those of previous studies demonstrating the behavioral effects of $8-0 \mathrm{H}-\mathrm{DPAT}$ injections and lesions in this area (Avanzi et al., 1998; Avanzi \& Brandão, 2001). At the end of the surgery, 120.000 U.I. of penicillin $G$ benzathine was given intramuscularly.

\section{Apparatus and procedure}

Matching: To record the amplitude of the startle response (ASR), we used two separated stabilimeter devices simultaneously. The rats were placed into a stabilimeter consisting of a wire-mesh cage $(16.5 \mathrm{x}$ $5.1 \times 7.6 \mathrm{~cm})$ suspended within a PVC frame $(25 \times 9$ $x 9 \mathrm{~cm}$ ), which was firmly placed on the response 
platform by 4 thumb-screws. The stabilimeter and platform were located inside a ventilated plywood sound-attenuating chamber $(64 \times 60 \times 40 \mathrm{~cm})$. The floor of the stabilimeter consisted of six $3.0-\mathrm{mm}$ diameter stainless steel bars spaced $1.5 \mathrm{~mm}$ apart. The startle reaction of the rats generated a pressure on the response platform and analog signals were amplified, digitized and analyzed by software (Startle reflex, version 4.10, Med Associates Inc., VT, USA) provided by the manufacturer of the equipment. The presentation and sequencing of the acoustic and visual stimuli were also controlled by the same software and an appropriate interface (Med Associates Inc., Vermont, USA). A loudspeaker, located $10 \mathrm{~cm}$ behind the wire-mesh cage, was used to deliver both acoustic startle stimuli and continuous background noise ( $55 \mathrm{~dB}$ SPL), and a white $6.0 \mathrm{~W}$ bulb located in the ceiling of the chamber delivered the visual stimuli. The startle stimulus was a $100 \mathrm{~dB}, 50 \mathrm{~ms}$ burst of white noise, having a rise-decay time of $5 \mathrm{~ms}$ and delivered through the same speakers as the background noise. The startle reaction was recorded within a timewindow of $200 \mathrm{~ms}$ after the startle stimulus onset. Calibration procedures were conducted before the experiments to ensure equivalent sensitivities of the response platforms. The behavior of the animals was recorded by a video camera (Everfocus, USA) positioned behind the stabilimeter, allowing the discrimination of all possible behavior, with the signal being relayed to a monitor in another room via a closed circuit. A red light bulb $(6.0 \mathrm{~W})$ was located on the floor of the isolation chamber to provide illumination for the camera. On the first 2 days, the animals were placed in the stabilimeter for $5 \mathrm{~min}$ for habituation, and then received a total of 30 startle stimuli with an intensity of $100 \mathrm{~dB}$ at a variable interstimulus interval of $30 \mathrm{~s}$ on average. Each matching session was of 20 min duration. For each experiment (pre- and post-training lesions or injections), the animals were matched into two equivalent groups, control or sham $(n=10)$ and injected or lesion $(n=10)$, based on their mean startle amplitude across the 30 noise bursts on the last matching day before training began.

Training. The animals were conditioned to light-CS in a box $(30 \times 20 \times 20 \mathrm{~cm})$ with ceiling, side and back walls being constructed of stainless steel and the front door made of transparent Plexiglas. The grid floor of this chamber consisted of stainless-steel rods spaced $1.2 \mathrm{~cm}$ apart. The box was located within a ventilated, soundattenuated chamber $(55 \times 55 \times 57 \mathrm{~cm})$. On each of 2 consecutive days, the animals were placed in the training cage, and 5 min later, each rat received 10 CS-US pairings, using a $4 \mathrm{~s}$ light $\mathrm{CS}$ coterminating with a $1 \mathrm{~s}, 0.6 \mathrm{~mA}$ footshock US (Kim \& Fanselow, 1992; Phillips \& LeDoux, 1992; Avanzi et al., 1998). The shocks were delivered through the training cage floor by a constant current generator built with a scrambler (Albarsh Instruments, Brazil). The CS was a white light presented through a bulb $(6.0 \mathrm{~W}, 127 \mathrm{~V})$ located in the ceiling of the chamber. Stimulus presentation was controlled by a microprocessor and an I/O board (Insight Equipment, Brazil). The inter-trial interval varied randomly between 60 and $240 \mathrm{~s}$. Each animal was removed $5 \mathrm{~min}$ after the last shock and was returned to its home cage. The duration of each training session was of $40 \mathrm{~min}$.

Testing. The testing sessions were conducted in the box where the animals had been shocktreated (same context), and afterward in a completely different experimental box used for the fear-potentiated startle procedure. All testing of the conditioning experiments was conducted during the light phase of the light/dark cycle. The behavior of the animals was recorded by a video camera (Everfocus) positioned in front of the observation chambers to allow the discrimination of all possible behavior, with the signal relayed to a monitor in another room via a closed circuit.

The testing sessions for contextual fear conditioning were conducted for $5 \mathrm{~min}$ in the box 
where the animals had been shocked (same context), without presentation of light-CS or foot shocks. A red light from a bulb $(6.0 \mathrm{~W})$ located on the back panel of the chamber was on during the session to provide minimal illumination of the box. The measure used to assess contextual fear was the time rats spent freezing during the test period. Freezing behavior was operationally defined as the total absence of movement of the body and vibrissae, accompanied by at least two of the following responses: arched back, retraction of the ears, piloerection, or exophthalmus. The freezing behavior was scored during testing and also subsequently from video tapes by an observer. In this way, the initial assessment of the testing sessions could be confirmed by scoring the videotapes later on.

Soon after having been tested in the fear contextual procedure, the rats were tested for potentiated startle. The sham or control and the lesion or drug microinjection animals were transferred to the startle testing cages, and $5 \mathrm{~min}$ later were presented with 60 startle stimuli (noise bursts) at a $30 \mathrm{~s}$ inter-stimulus interval. The intensity of the startle stimulus used was $100 \mathrm{~dB}$. Half of the startle stimuli were presented in the absence of the CS to provide a baseline (noisealone trials), and the other half were presented in the presence of the CS (light-noise trials). In the light-noise trials, the startle stimulus was presented in the last second of a $4 \mathrm{~s}$ presentation of light, similar to the training sessions. Startle response amplitudes collected from this experiment were stored on computer hard disk and transferred to tables in a spreadsheet program (Excel; Microsoft Corp.) for the off-line analysis.

\section{Histology}

Upon completion of the experiments, the animals were overdosed with urethane and perfused intracardially with saline, followed by $10 \%$ formalin. The brains were removed and immersionfixed for $3 \mathrm{~d}$ with $8 \%$ paraformaldehyde in phosphate-buffered saline containing $20 \%$ sucrose. Serial $45-\mu \mathrm{m}$ brain sections were taken on a freezing microtome, thaw-mounted on gelatinized slides, and stained with methylene blue. Only animals with electrolytic lesions in the confines of the MRN in three consecutive planes of the Paxinos and Watson Atlas (1997) were included in this study. Using this criterion. we discarded eight animals from Experiment 1 (three from the pretraining and five from the post-training groups).

\section{Experiment 1}

In this experiment, we tested whether MRN electrolytic lesions, made before or after the training sessions, would affect the freezing behavior to contextual stimuli or the fear-potentiated startle to light-CS, used as foreground stimuli. Pre-training groups received MRN electrolytic or sham lesions 7 $\mathrm{d}$ before the training sessions (Experiment 1A). Post-training lesion groups received electrolytic or sham lesions on the day after the training sessions (Experiment 1B). A period of $1 \mathrm{wk}$ was allowed for post-operative recovery. The animals $(n=40)$ were matched into two equivalent groups, sham $(\mathrm{n}=20)$ and lesion $(n=20)$, based on their mean startle amplitude across 30 presentations of acoustic stimuli $(100 \mathrm{~dB})$ on the last matching session before the training sessions. Training and testing sessions were conducted as described in the Apparatus and Procedure section.

\section{Statistical analysis}

The startle response amplitudes for each trial type (noise-alone vs. light-noise) were averaged for each animal across the entire session and used as the data for statistical analysis. For each experiment, a two-way analysis of variance (ANOVA) was conducted on the mean startle 
response, with groups (sham or control vs. lesion or drug microinjection) as a between-subjects factor and trial-type as a within-subjects factor. Significant comparisons were tested with the Newman-Keuls test. The Student's $t$-test was used to assess the differences between groups in the contextual fear conditioning experiments.

\section{RESULTS}

Figure 1 shows a transverse section from the midbrain of a typical rat in the MRN lesion group. The size of the lesion was largely restricted to the confines of the MRN in all cases. The most noticeable behavior expressed by all animals in this study during the training sessions was a burst of activity, together with jumps during the shocks. These responses were interspersed with freezing during the inter-trial period.

\section{Experiment 1A}

In the contextual conditioning experiments, the total amount of freezing responses recorded in the testing sessions was evaluated by the Student's $t$ test. Figure 2 (left) displays the mean freezing for animals that underwent electrolytic or sham lesions before the training sessions and were tested ten days later in the same context. Statistical analysis showed significant differences between

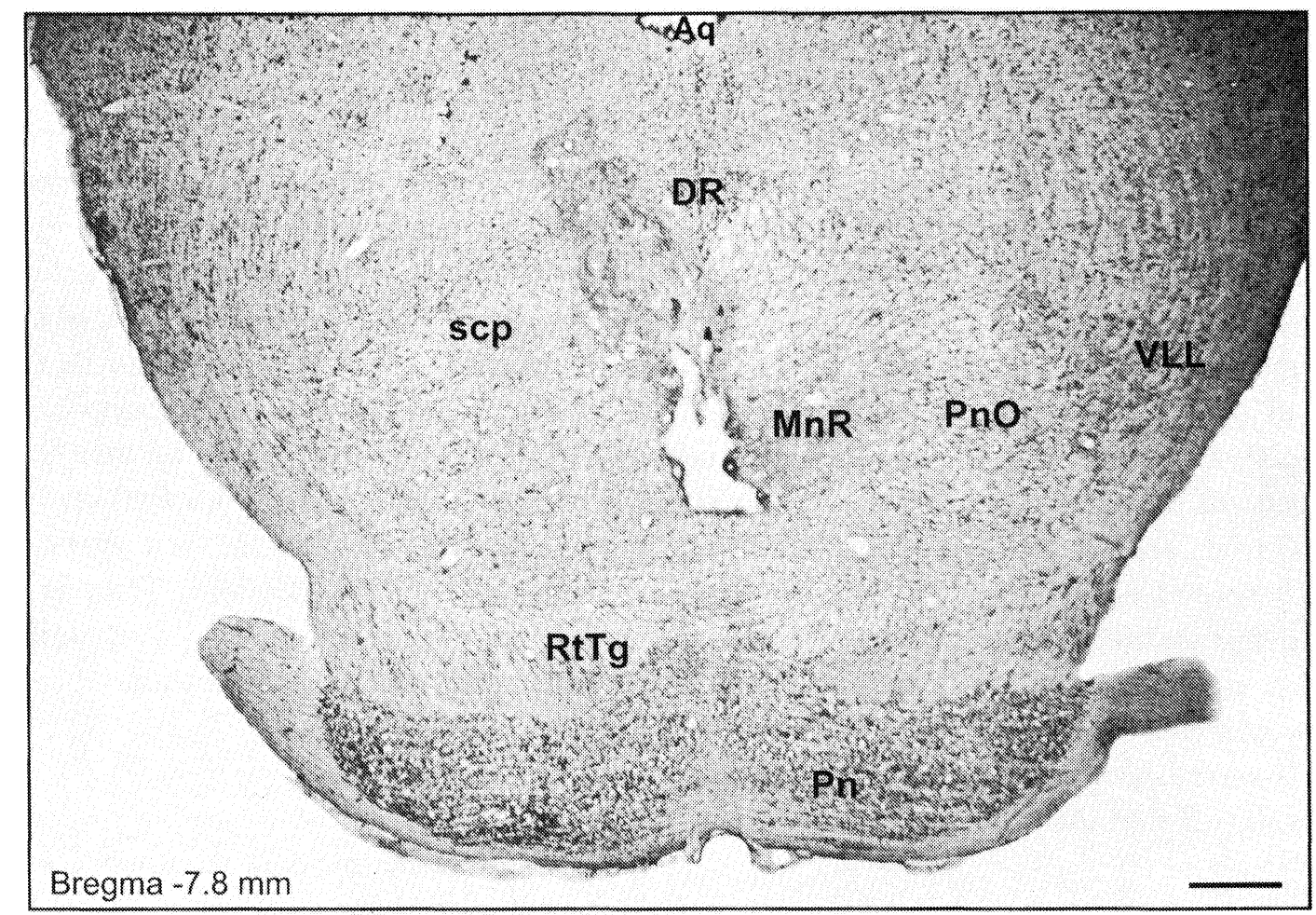

Fig. 1: Photomicrograph showing a typical example of electrolytic lesions of the median raphe nucleus. The section shown is $-7.8 \mathrm{~mm}$ behind bregma according to the Paxinos and Watson atlas (1997). MnR= median raphe nucleus, $\mathrm{scp}=$ superior cerebellar peduncle, $\mathrm{PnO}=$ pontine reticular nucleus, $\mathrm{DR}=$ dorsal raphe nucleus, $\mathrm{Pn}=$ pedunculopontine nucleus, $\mathrm{VLL}=$ ventral nucleus of the lateral lemniscus, $\mathrm{RtTg}=$ Reticulotegmental nucleus of pons, $\mathrm{Aq}=$ aqueduct. $\mathrm{Bar}=350 \mu \mathrm{m}$. 
groups $(\mathrm{t}=3.89,18$ d.f., $\mathrm{p}<0.01)$, indicating a significant decrease in the time of freezing spent by rats with electrolytic lesions into the MRN compared with sham-lesioned rats. The magnitude of the startle reflex in the lesioned and sham groups of rats was evaluated by a two-way ANOVA. This analysis revealed that there was a main effect of electrolytic lesion, $\mathrm{F}_{1,18}=4.62$, $\mathrm{p}<0.05$, indicating significant effects in the sham group compared with the lesion group. There was a main effect for trial-type, $F_{1,18}=15.82, p<0.001$, indicating a greater response to light-noise than to noise-alone condition. There was a significant groups vs. trial-type interaction $\left(\mathrm{F}_{1,18}=6.73\right.$, $\mathrm{p}<0.01$ ), indicating that the effects of trial-type were dependent on the group of animals tested. Post-hoc comparisons by the Newman-Keuls method revealed that light-CS enhanced the startle response to noise in the sham-lesion group $(\mathrm{p}<0.01)$. On the other hand, startle reflex to noise alone was not statistically different in the sham and lesion groups $(p>0.05)$. The effects of pretraining lesions of the MRN on the potentiated startle reflex are illustrated in Figure 2 (right)

\section{Experiment 1B}

Figure 3 (left) displays the mean freezing for animals that underwent electrolytic lesions or sham lesions after the training sessions. Here also, freezing was the most remarkable response of control rats when placed in the cage where they had previously received foot-shocks before the surgery. Statistical analysis showed significant differences between the groups $(t=7.78,18$ d.f., $p<0.001)$, indicating a significant decrease in the time of freezing spent by rats with electrolytic lesions into the MRN compared with sham-lesioned rats. The magnitude of the startle reflex in lesioned and sham groups of rats is illustrated in Fig. 3 (right). Two-way ANOVA revealed that there was no effect of electrolytic lesion, $F_{1,18}=1.79, p>0.05$, indicating no significant differences between the sham and lesion groups. There was a main effect for trial type, $F_{1,18}=49.65, p<0.001$, indicating a greater response to light-noise than to noise -alone condition. There was no significant groups vs. trial-type interaction $\left(\mathrm{F}_{1,18}=2.91, \mathrm{p}>0.05\right)$. Posthoc comparisons with Newman-Keuls method revealed that light-CS enhanced the startle response to noise in both sham and lesion groups $(p<0.01)$. On the other hand, startle reflex to noise alone was not statistically different in the sham and lesion groups ( $p>0.05)$.

\section{Experiment 2}

The animals $(n=40)$ were matched into two equivalent groups, control or sham $(\mathrm{n}=10)$ and injected or lesion $(n=10)$, based on their mean startle amplitude across the 30 noise bursts on the last matching day before training began. Two days after the excitotoxic lesions and $15 \mathrm{~min}$ after 8OH-DPAT injections, the animals were conditioned in the training cage and $24 \mathrm{~h}$ later tested as described in General Methods. Five animals with injection sites of 8-OH-DPAT in the neighboring regions of the MRN were included as an anatomical control for the effects of injections inside the nucleus.

Microinjection Procedure. One week after the surgery, the animals were anesthetized again with tribromoethanol $(250 \mathrm{mg} / \mathrm{kg}$, i.p., Sigma). The injection needle was a thin dental needle (o.d. 0.3 $\mathrm{mm}$ ) connected by PE10 polythene tubing to a $5 \mu \mathrm{l}$ Hamilton syringe mounted in an infusion pump (Harvard Apparatus, South Natick, MA). The injection needle was introduced through the guide cannula until its lower end was $2 \mathrm{~mm}$ below the guide cannula. Neurotoxic lesions were produced by NMDA (Sigma; $6 \mu \mathrm{g} / 0.6 \mu \mathrm{l}$ physiological saline). Infusions were made at $0.1 \mu \mathrm{l} / \mathrm{min}$ and the cannula left in place for a further $2 \mathrm{~min}$, to allow the toxin to diffuse away from the tip. 


\section{MRN LESION PRE-TRAINING}
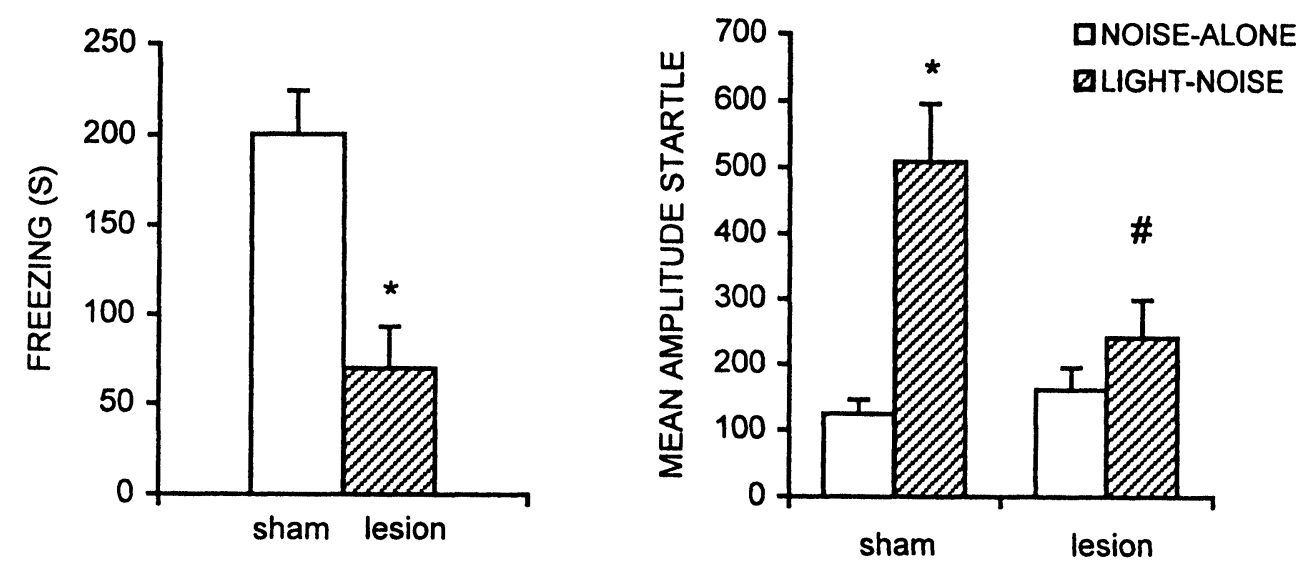

Fig. 2: Left: Effects of pre-training electrolytic lesion of the MRN on time (sec) of freezing in rats placed into the chamber where they had received footshock. Control animals received sham lesions. Mean \pm S.E.M. of 10 animals in sham and lesioned groups. ${ }^{*} \mathrm{p}<0.01$, Student' $t$-test. Right: Effects of pre-training lesions of the MRN on the mean amplitude startle response as compared to control animals (sham lesion). * Different from noise-alone condition, and \# different from the respective control group ( $p<0.05$, Newman-Keuls test). $n=10$ in the sham group and in the lesioned group.

\section{MRN LESION POST-TRAINING}
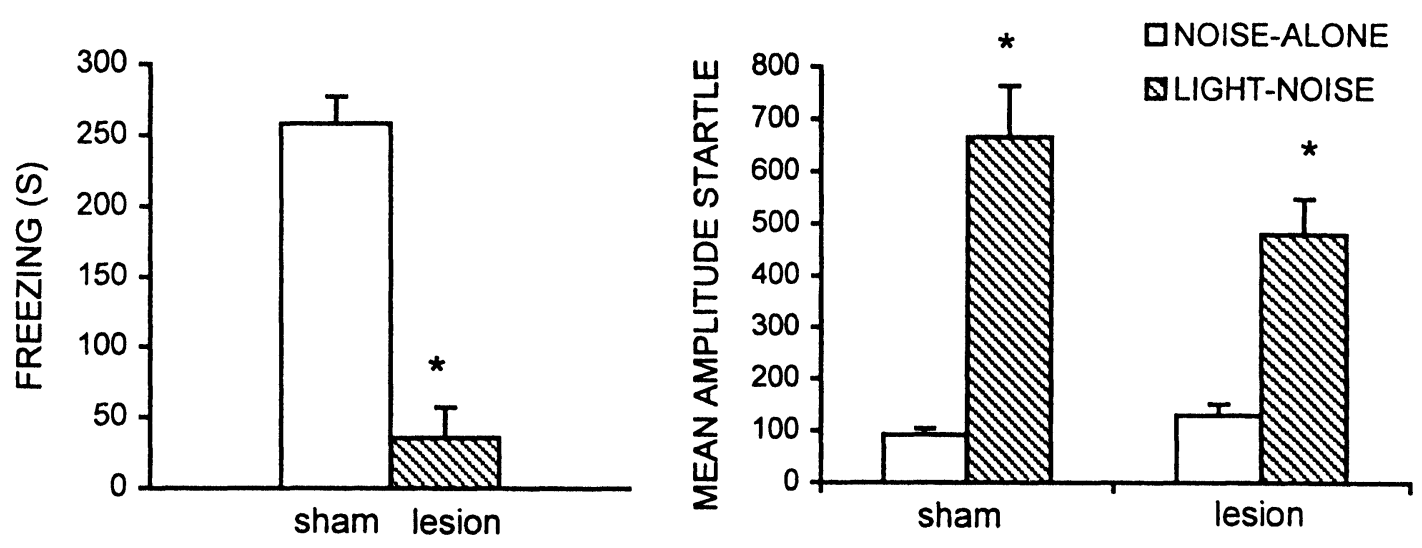

Fig. 3: Left: Effects of post-training electrolytic lesion of the MRN on time (sec) of freezing in rats placed into the chamber where they had received foot-shocks. Control animals received sham lesions. Mean \pm S.E.M. of 10 animals in sham and lesioned groups. ${ }^{*} \mathrm{p}<0.001$, Student's t-test. Right: Effects of post-training lesions of the MRN on the mean amplitude startle response as compared to control animals (sham lesion). * Different from noise-alone condition ( $\mathrm{p}<0.05$, Newman-Keuls test). $\mathrm{n}=10$ in both groups. 


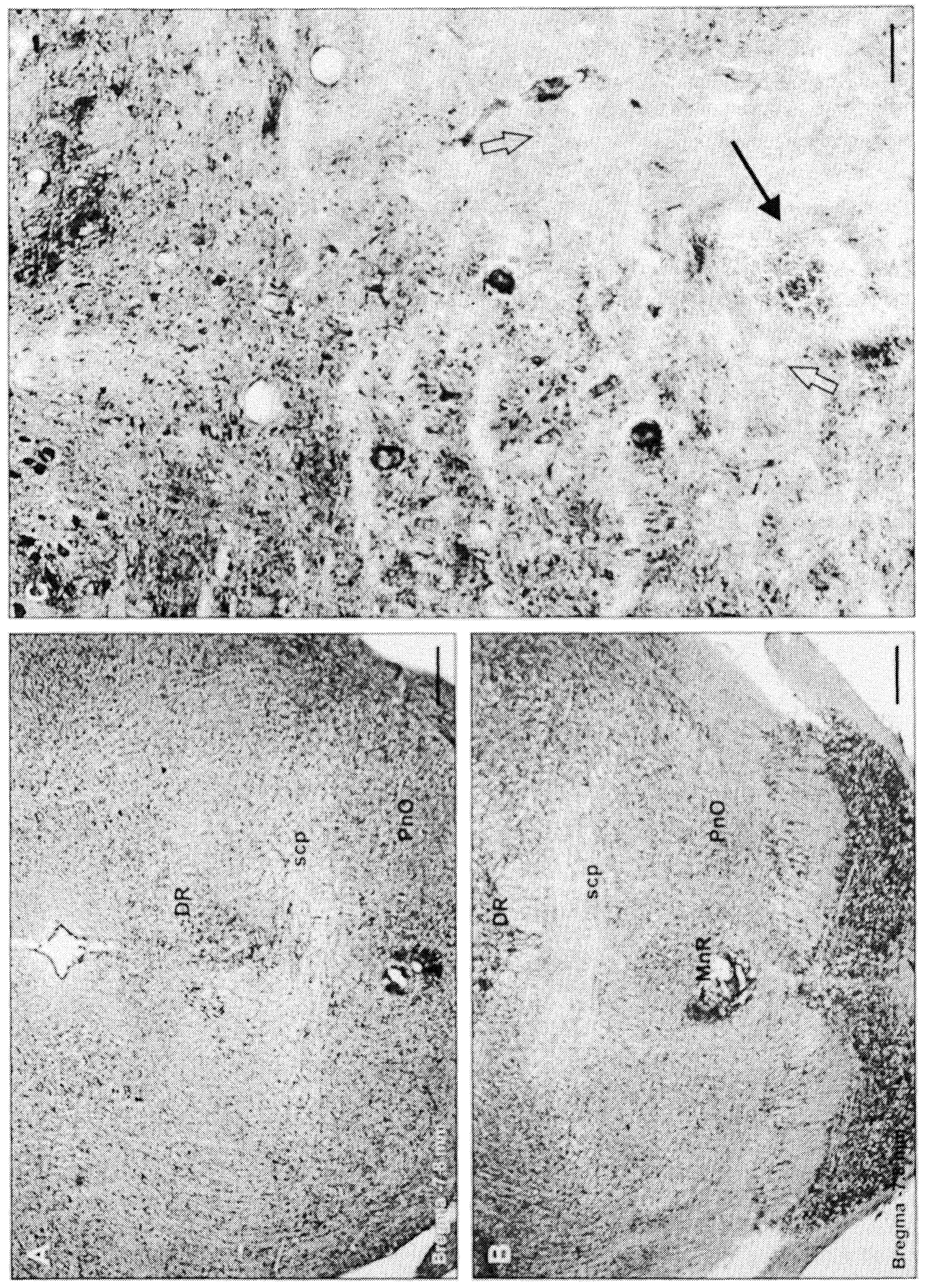

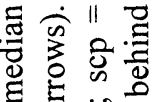
สิ

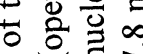

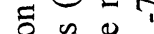
홍

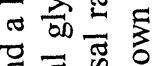

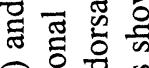
ङ

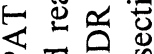

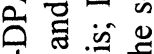
齐合矛占 光育就. त व ธี 빼 总产远 节艺的令

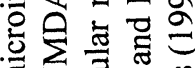

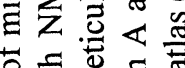

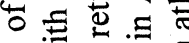

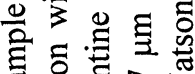

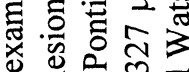
(1)

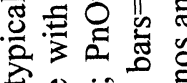

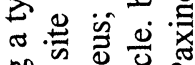
$\stackrel{\infty}{\infty}<\frac{\pi}{0}$ 绕寻五 के 苍产恋

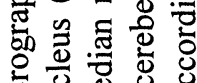

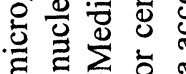

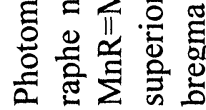
$\ddot{\gamma}$ in 
Control groups of animals were similarly injected with physiological saline. The same procedure was followed for microinjections of 8OH-DPAT (RBI; $1 \mu \mathrm{g} / 0.2 \mu$ l physiological saline) into the MRN, with the exception that the drug was administered to anaesthetized animals. Microinjection of the same volume of physiological saline also served as vehicle control. The displacement of an air bubble inside the polyethylene (PE-10) catheter connecting the syringe needle to the intracerebral needle was used to monitor the microinjection.

Results. The injection cannulae were located inside the MRN of all animals used in this study (Figs. 4A and 4B). Histological examination of the tissue sections demonstrated that infusion of NMDA into the MRN produced an extensive destruction of neuronal cell bodies along with reactional glyosis (Fig. 4C). As the amounts of freezing and fear-potentiated startle responses in rats injected with saline $48 \mathrm{~h}$ (control for NMDA) or $15 \mathrm{~min}$ (control for 8-OH-DPAT) before the training sessions were not statistically different, these groups were pooled together and treated as just one control group. Figure 5 (left) shows the mean freezing for animals that received NMDA or 8-OH-DPAT microinjections into the MRN before the training sessions, and tested $24 \mathrm{~h}$ later in the same context. Freezing was the most remarkable response of control rats when placed in the experimental chamber where they had received foot-shocks previously. A one-way ANOVA applied to treatments (saline, 8-OH-DPAT and NMDA microinjections) revealed a significant effect of MRN microinjections, $F_{2,37}=9.69, p<0.001$. Posthoc tests revealed significant differences in the amount of freezing between control and NMDA or 8-OH-DPAT groups tested in the same context $(\mathrm{p}<0.01$ for NMDA and 8-OH-DPAT).

Figure 5 (right) shows the effects of pretraining injections of saline, NMDA and 8-OHDPAT into the MRN on the magnitude of the

\section{MRN MICROINJECTIONS}
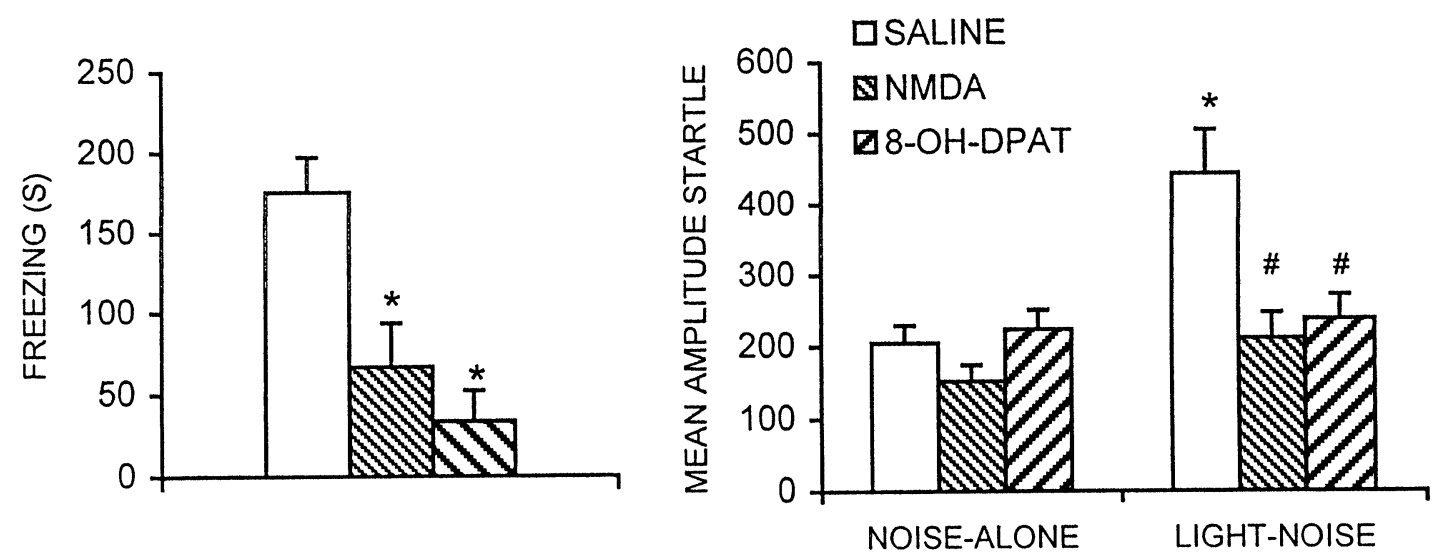

Fig. 5: Left: Effects of pre-training injections of NMDA and 8-OH-DPAT into the MRN on time (sec) of freezing in rats placed into the chamber where they had received footshock. Control animals received saline microinjections. Mean \pm S.E.M. of 10 animals in control and treated groups. ${ }^{*} \mathrm{p}<0.01$, Newman-Keuls test. Right: Effects of pre-training injections of NMDA and 8-OH-DPAT into the MRN on the mean amplitude startle response as compared to control animals (saline). * Different from noise-alone condition. \# Different from the corresponding control condition $(p<0.05$, Newman-Keuls test). $n=10$ in both groups. 
startle reflex in control, NMDA or 8-OH-DPAT injected-groups.

Two-way ANOVA revealed that there was a main effect of groups, $F_{2,37}=7.59, p<0.01$, indicating significant reduction in the druginjected groups compared with the control-group. There was a main effect for trial type, $\mathrm{F}_{2,37}=19.32$, $\mathrm{p}<0.001$, indicating a greater response to lightnoise than to noise-alone condition. There was a significant groups vs. trial type interaction $\left(\mathrm{F}_{2,37}=\right.$ 10.33, $p<0.001)$, indicating that the effects of trial type were dependent on the group of animals tested. Post-hoc comparisons with the NewmanKeuls method revealed that light-CS enhanced startle reflex to noise only in the saline group $(\mathrm{P}<0.001)$. On the other hand, startle reflex to noise-alone was not statistically different between groups ( $\mathrm{p}>0.05)$.

In five animals, the injection cannulae were outside the MRN, in the neighboring regions dorsal or lateral to it. Injections of 8-OH-DPAT into these sites did not significantly change conditioned freezing to background stimuli $(116.60 \pm 53.4)$ or fear-potentiated startle $(217.60$ \pm 39.9 for noise alone and $446.40 \pm 123.6$ for light plus noise) in relation to the controls injected with saline into the MRN.

\section{DISCUSSION}

In the present experiments, that electrolytic lesion of the MRN inhibited the freezing behavior to background cues in the chamber where the animals had previously experienced footshock provides evidence for an involvement of the MRN in contextual conditioned fear. The results cannot be attributed to changes in footshock sensitivity, as it has already been shown that lesions of the MRN did not affect freezing behavior immediately after shock presentations even though the same rats showed a deficit in freezing measured $48 \mathrm{~h}$ later, without footshock (Melik et al., 2000; Avanzi \& Brandão, 2001). The results presented here show that when the box provides a true context for the conditioned stimulus-unconditioned stimulus (CSUCS) conditioning, the median raphe nucleus plays an important role.

Many studies have shown that MRN is critically involved in the regulation of motor, defensive behaviors, and autonomic responses associated with fear (Graeff \& Silveira-Filho, 1978; Gray, 1987; Hillegaart \& Hjort, 1989; Hillegaart, 1990). One pathway that has been proposed to be responsible for these responses is the efferents from this nucleus that reach mainly the septum and hippocampus, via the medial forebrain bundle (Bobillier et al., 1975; Bobillier et al., 1976; Geyer et al., 1976; Molliver, 1987; Vertes et al., 1999). In line with the present findings, a lack of Pavlovian association between context and footshock was also observed when the hippocampus was lesioned before conditioning (Philips \& LeDoux, 1992). Thus, MRN-hippocampus pathways may be critical for the retention of contextual fear conditioning, but not for all associative fear memories. In fact, the hippocampus is widely believed to be essential for learning about context in which conditioning occurs (Maren et al., 1997; Maren \& Holt, 2000; Gewirtz et al., 2000; Fanselow, 2000). On the basis of this and much other evidence, it has been suggested that these pathways are part of the so-called behavioral inhibition system (Gray, 1987). In accordance with this proposal, electrical stimulation of the MRN suppresses positively reinforced operant responses, and at the same time elicits crouching, defecation, micturition, piloerection, and other symptoms that are characteristic of emotional behavior in the rat (Graeff \& Silveira-Filho, 1978). The septo-hippocampal system seems to be mainly related to initiation and maintenance of the proper functions that are necessary for coping with stressful situations, as well as to freezing behavior 
(Hillegaart \& Hjort, 1989; Maren, 1997, De Almeida et al., 1998; Maren \& Holt, 2000; Gewirtz et al., 2000; Fanselow, 2000).

In the present study, animals bearing pretraining MRN lesions exhibited less freezing and fear-potentiated startle than did sham-lesioned animals. The present findings cannot be attributed to lesions of fibers of passage, as NMDA microinjections into the MRN produced similar results to those obtained with electrolytic lesions. The reduction of both kinds of response leads us to suggest that fear to background (context) or to foreground (light-CS) stimuli share the same neural mechanisms for the acquisition of the conditioned fear responses. Animals bearing posttraining MRN lesions had a significant disruption of the expression of freezing, however, whereas the response to the explicit cue remained unchanged in the fear potentiated-startle test. Besides, the data obtained suggest that serotonergic pathways from the MRN may be involved in the elaboration of defense responses related to conditioned fear triggered either by contextual or brief light $\mathrm{CS}$, since the MRN microinjection of 8-OH-DPAT, a 5- $\mathrm{HT}_{1 \mathrm{~A}}$ agonist that decreases the neuronal impulse flow by the activation of $5-\mathrm{HT}_{1 \mathrm{~A}}$ somatodendritic autoreceptors onto raphe cells, caused similar effects to the lesions at the median raphe nucleus. These effects seem to be related to the kinds of aversive stimuli prevalent in the environment because 8-OH-DPAT injections into the MRN did not affect fear-conditioned responses to a tone previously associated with footshock (Avanzi \& Brandão, 2001). Therefore, the fear responses generated in these two types of test have distinct neural substrates, the neurobiological bases of which remain to be described. A possible explanation emerges from the observation that the responses of freezing, arousal, and increased attention generated during anxiety-related processes can be organized by distinct circuits (Gray, 1987, 2000). As a result, different neural circuits could be recruited at the level of the MRN during the acquisition of the contextual fear conditioning and fear-potentiated startle. Thus, the acquisition of these fear-related responses could diverge at the level of the MRN. In line with this proposal, hippocampal lesions attenuate contextual freezing without any effect on fear-potentiated startle, whereas electrolytic or chemical lesions of the amygdala block the expression of fear-potentiated startle to explicit cues (Hithcock \& Davis, 1986; Sananes \& Davis, 1992; Davis et al., 1994; Campeau \& Davis, 1995; Philips \& LeDoux, 1994; McNish et al., 1997).

Some have argued that the selection of the appropriate response to threatening situations produced by learned cues from the animal's repertoire is dependent on forebrain structures, particularly the amygdala (Davis, 1992, 1994; Fanselow et al., 1995). The amygdala plays a crucial role in the acquisition and expression of fear to the conditioned stimulus and is the interface between sensory systems that carry information about the CS and UCS, and different motor and autonomic systems that control conditioned reactions (Davis et al., 1992, 1994; LeDoux, 1995; Fendt \& Fanselow, 1999). Our present findings have obvious implications for the understanding of the functioning of the sensorymotor interface existing in the amygdala. Indeed, besides the well-known projections to the hippocampus and septum, fibers from the MRN branch off as they course through the medial forebrain bundle and continue through the internal capsule into the amygdala (Nieuwenhuys, 1985). Although freezing is a prominent response for the contextual fear conditioning, which seems to be regulated by MRN-hippocampus pathways, freezing does not seem to be crucial for the amygdala-dependent enhancement of the startle reflex by explicit aversive cues.

Conditioned freezing to background stimuli has been shown to be time-dependent (Kim \& 
Fanselow, 1992). The results of the present study support this contention because MRN lesions performed soon after training disrupted it. This evidence further strengthens the proposal of a role for the MRN-hippocampus pathway in contextual fear conditioning, with a slow transfer of the contextual aversive information to other structures. Actually, the temporally restricted role of the hippocampus in memory storage has already been proposed because conditional fear to contextual cues of the experimental chamber, as assessed by freezing, was disrupted when hippocampal lesions were made 1 day, but not 1 week, after conditioning (Kim \& Fanselow, 1992). On the other hand, the acquisition of the aversive information in the fearpotentiated startle test does not seem to recruit the same mechanisms because MRN lesions made one day after the training do not affect this response.

One possibility that emerges is the occurrence of a rapid transfer of information through MRNamygdala connections. Other findings indicating different neural substrates for conditioning to background and foreground stimuli have also been reported. Indeed, in a series of experiments that examined the effects of variations in US intensity on conditioning to explicit and contextual stimuli, it was observed that at low intensities of the US, conditioning developed only to the explicit CS, whereas contextual conditioning required higher US intensities (Philips \& LeDoux, 1992). It seems that the MRN may play some role in selecting which of the pathways originated therein is particularly relevant to the available environmental stimuli, whether they are contextual or explicit cues.

For auditory stimuli, the CS is transmitted through the auditory system to the medial geniculate body and from there to the lateral nucleus of the amygdala (Philips \& LeDoux, 1992). The amygdala may also receive sensory information from several sources that act in parallel, such as the perirhinal cortex for visual stimuli or the temporal cortex for auditory stimuli (Campeau \& Davis, 1995; LeDoux,
1995; Fendt \& Fanselow, 1999). In support of its involvement in the production of fear responses, amygdaloid lesions reduce or abolish performance of virtually all measures of conditional fear, including freezing behavior (Blanchard \& Blanchard, 1972; LeDoux et al., 1988), potentiated startle (Hitchcock \& Davis, 1986) and analgesia (Helmstetter, 1992).

Taken together, the data presented here show that while pre-training lesions of the MRN disrupt contextual freezing and fear-potentiated startle, post-training lesions inhibit freezing to the contextual CS without changing the fearpotentiated startle. Therefore, freezing seems to be a prominent response for the contextual fear conditioning but not for the fear-potentiated startle. Because pre-training injections of $8-\mathrm{OH}-$ DPAT into the median raphe nucleus preclude fear responses in the contextual fear conditioning and fear-potentiated startle, 5-HT mechanisms appear to be involved in the acquisition of aversive information in both situations. Nevertheless, this nucleus is not involved in the fear conditioning to tone, as previously shown by work performed in this and in other laboratories.

\section{ACKNOWLEDGMENTS}

This work was supported by FAPESP (Proc. No. 98/11197-2 and 02/03705-0). R.C.B. Silva and V. Avanzi are the recipients of doctoral scholarships from FAPESP.

\section{REFERENCES}

Andrade TG, Graeff FG. 2001. Effect of electrolytic and neurotoxic lesions of the median raphe nucleus on anxiety and stress. Pharmacol Biochem Behav 70: 1-14.

Avanzi V, Castilho VM, de Andrade TG, Brandão ML. 
1998. Regulation of contextual conditioning by the median raphe nucleus. Brain Res 790: 178-184.

Avanzi V, Brandão ML. 2001. Activation of somatodendritic 5-HT(1A) autoreceptors in the median raphe nucleus disrupts the contextual conditioning in rats. Behav Brain Res 126: 175-184.

Azmitia EC, Segal M. 1978. An autoradiographic analysis of the differential ascending projections of the dorsal and median raphe nuclei in the rat. $\mathrm{J}$ Comp Neurol 179: 641-667.

Blanchard DC, Blanchard RJ. 1972. Innate and conditioned reactions to threat in rats with amygdaloid lesions. J Comp Physiol Psychol 81: 281-290.

Blier P, de Montigny C. 1987 Modification of 5-HT neuron properties by sustained administration of the 5-HT1A agonist gepirone: electrophysiological studies in the rat brain. Synapse 1: 470-480.

Bobillier P, Petijean F, Salvert D, Ligier M, Seguin S. 1975. Differential projections of the nucleus raphe dorsalis and nucleus raphe centralis as revealed by autoradiography. Brain Res 85: 205-210.

Bobillier P, Seguin S, Petitjean F, Salvert D, Touret M, Jouvet M. 1976. The raphe nuclei of the cat brain stem: a topographical atlas of their efferent projections as revealed by autoradiography. Brain Res 113: 449-486.

Brown JS, Kalish HI, Farber IE. 1951. Conditioned fear as revealed by magnitude of startle response to an auditory stimulus. J Exp Psychol 41: 317-328.

Campeau S, Davis M. 1995. Involvement of the central nucleus and basolateral complex of the amygdala in fear conditioning measured with fear-potentiated startle in rats trained concurrently with auditory and visual conditioned stimuli. J Neurosci 15: 2301-2311.

Davis M. 1992. The role of the amygdala in conditioned fear. In Aggleton JP, ed, The Amygdala: Neurobiological Aspects of Emotion, Memory and Mental Dysfunction. New York, NY, USA: WileyLiss, 255-305.

Davis M, Rainnie D, Cassell M. 1994. Neurotransmission in the rat amygdala related to fear and anxiety. Trends Neurosci 17: 208-214.

De Almeida RM, Giovenardi $\mathrm{M}$, Charchat $\mathrm{H}$, Lucion AB. 1998. 8-OH-DPAT in the median raphe nucleus decreases while in the medial septal area it may increase anxiety in female rats. Neurosci Biobehav Rev 23: 259-264.

Fanselow MS, Decola JP, De Oca BM, LandeiraFernadez J. 1995. Ventral and dorsolateral regions of the midbrain periaqueductal gray (PAG) control different stages of defensive behavior: Dorsolateral PAG lesions enhance the defensive freezing produced by massed and immediate shock. Aggress Behav 21: 63-67.

Fanselow MS. 2000. Contextual fear, gestalt memories, and the hipoccampus. Behav Brain Res 110: 73-81.

Fendt M, Fanselow MS. 1999. The neuroanatomical and neurochemical basis of conditioned fear. Neurosci Biobehav Rev 23: 743-760.

Gewirtz JC, McNish KA, Davis M. 2000. Is the hippocampus necessary for contextual fear conditioning? Behav Brain Res 110: 83-95.

Geyer MA, Puerto A, Dawsey WJ, Knapp S, Bullard WP, Mandell AJ. 1976. Histologic and enzymatic studies of the mesolimbic and mesostriatal serotonergic pathways. Brain Res 106: 241-256.

Graeff FG, Silveira Filho NG. 1978. Behavioral inhibition induced by electrical stimulation of the median raphe nucleus of the rat. Physiol Behav 21, $477-484$.

Gray JA. 1987. The Psychology of Fear and Stress. Cambridge, UK: Cambridge University Press.

Gray JA, McNaughton N. 2000. Fundamentals of the septo-hippocampal system. In: Gray JA, McNaughton $\mathrm{N}$, eds, The Neuropsychology of Anxiety: An enquiry into the functions of septohippocampal system, $2^{\text {nd }}$ edition. Oxford, UK: Oxford University press, 204-232.

Helmstetter FJ. 1992. The amygdala is essential for the expression of conditional hypoalgesia. Behav Neurosci 106: 518-528.

Hillegaart V, Hjorth S. 1989. Median raphe, but not dorsal raphe, application of the $5-\mathrm{HT}_{1 \mathrm{~A}}$ agonist 8-OH-DPAT stimulates rat motor activity. Eur J Pharmacol 160: 303-307.

Hillegaart V. 1990. Effects of local application of 5HT and 8-OH-DPAT into the dorsal and median raphe nuclei on motor activity in the rat. Physiol Behav 48: 143-148.

Hitchcock JM, Davis M. 1986. Lesions of amygdala, but not of the cerebellum or red nucleus, block conditioned fear as measured with the potentiated startle paradigm. Behav Neurosci 100: 11-22.

Kim JJ, Fanselow MS. 1992. Modality-specific retrograde amnesia of fear. Science 256(5057): 675-677.

Kiser RS, Lebovitz RM. 1975. Monoaminergic mechanisms in aversive brain stimulation. Physiol Behav 15: 47-53.

LeDoux JE, Iwata J, Cicchetti P, Reis DJ. 1988. Different 
projections of the central amygdaloid nucleus mediate autonomic and behavioral correlates of conditioned fear. J Neurosci 8: 2517-2529.

LeDoux JE. 1995. Emotion: clues from the brain. Ann Rev Psychol 46: 209-235.

Maren S, Aharonov G, Fanselow MS. 1997. Neurotoxic lesions of the dorsal hippocampus and Pavlovian fear conditioning in rats. Behav Brain Res 88: 261-274.

Maren S, Holt W. 2000. The hippocampus and contextual memory retrieval in Pavlovian conditioning. Behav Brain Res 110: 97-108.

McNish KA, Gewirtz JC, Davis M. 1997. Evidence of contextual fear after lesions of the hippocampus: a disruption of freezing but not fear-potentiated startle. J Neurosci 17: 9353-9360.

Molliver ME. 1987. Serotonergic neuronal systems: what their anatomic organization tells us about function. J Clin Psychopharmacol 7(Suppl): 3S-23S.

Melik E, Babar-Melik E, Ozgunen T, Binokay S. 2000. Median raphe nucleus mediates forming long-term but not short term contextual fear conditioning in rats. Behav Brain Res 112: 145-150.

Nieuwenhuys R. 1985. The Chemoarchitecture of the Brain. Berlin, Germany: Springer-Verlag; 33-41.

Papaioannou VE, Fox JG. 1993. Efficacy of tribromo- ethanol anesthesia in mice. Lab Anim Sci 43: 189 192.

Paxinos G, Watson C. 1997. The Rat Brain in Stereotaxic Coordinates, 3rd Edition. San Diego, California, USA: Academic Press.

Phillips RG, LeDoux JE. 1992. Differential contributions of amygdala and hippocampus to cued and contextual fear conditioning. Behav Neurosci 106: 274-285.

Phillips RG, LeDoux JE. 1994. Lesions of the dorsal hippocampal formation interfere with background but not foreground contextual fear conditioning. Learn Mem 1: 34-44.

Sananes CB, Davis M. 1992. N-methyl-D-aspartate lesions of the lateral and basolateral nuclei of the amygdala block fear-potentiated startle and shock sensitization of startle. Behav Neurosci 106: 72-80.

Srebro B, Lorens SA. 1975. Behavioral effects of selective midbrain raphe lesions in the rat. Brain Res 89: 303-325.

Tye NC, Everitt BJ, Iversen SD. 1977. 5-hydroxytriptamine and punishment. Nature 268(5622): 741-743.

Vertes RP, Fortin WJ, Crane AM. 1999. Projections of the median raphe nucleus in the rat. $\mathrm{J}$ Comp Neurol 407: 555-582. 

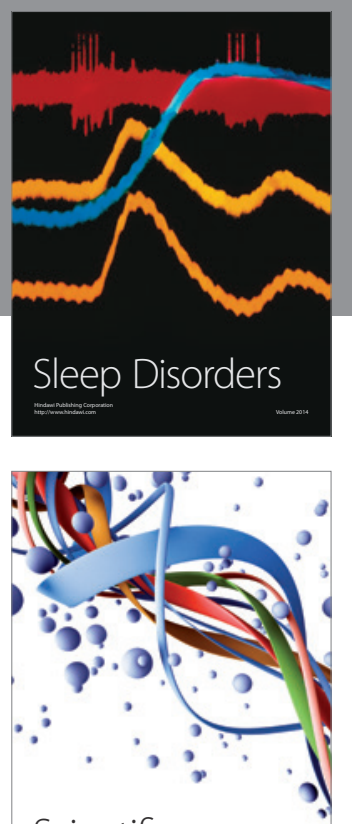

Scientifica
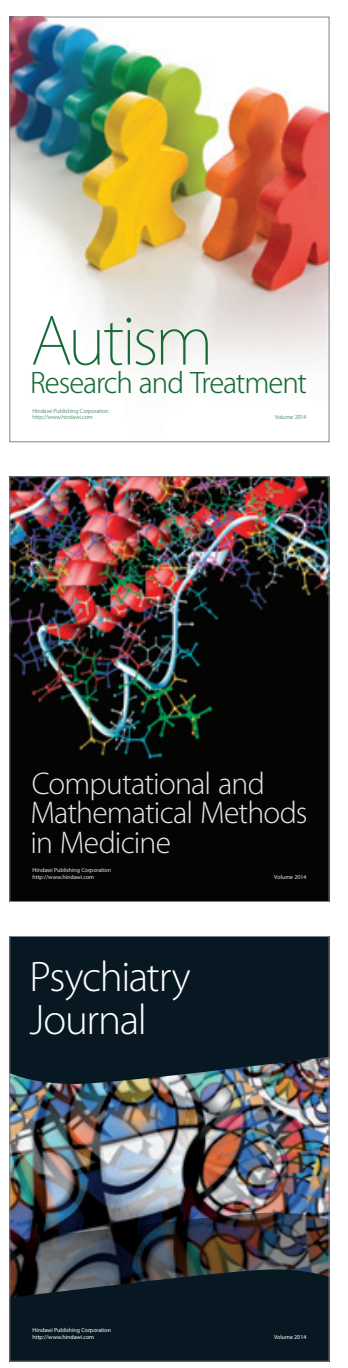
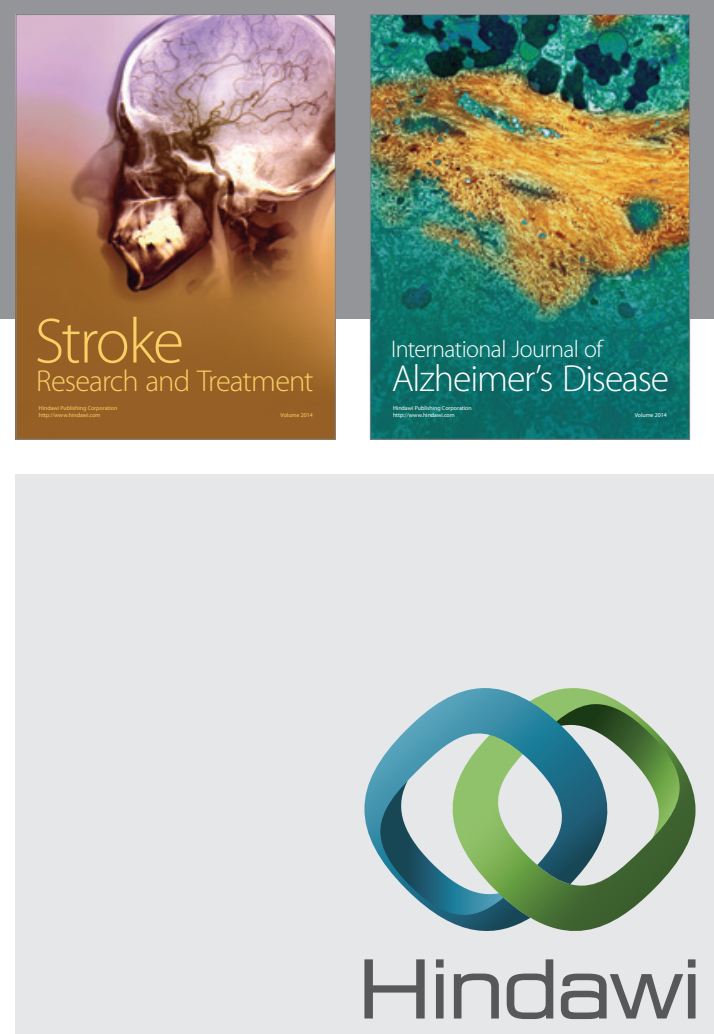

Submit your manuscripts at

http://www.hindawi.com
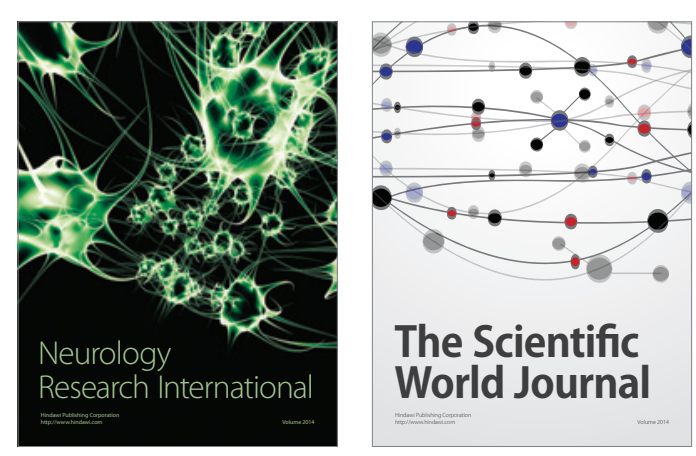

The Scientific World Journal

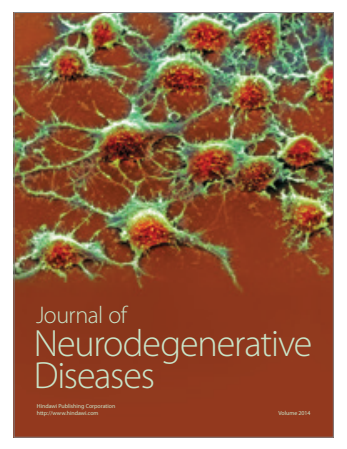

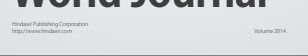

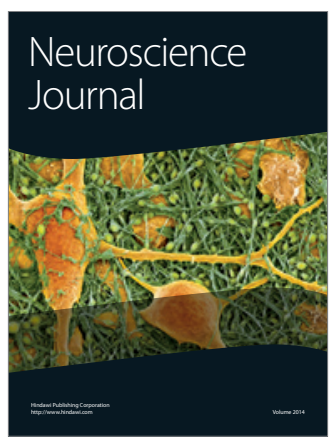

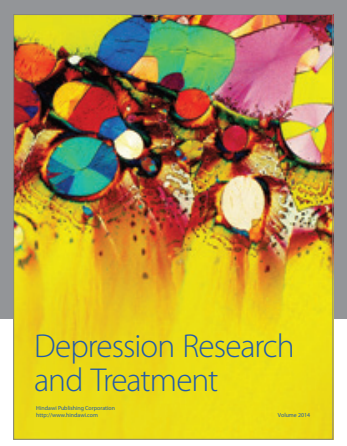
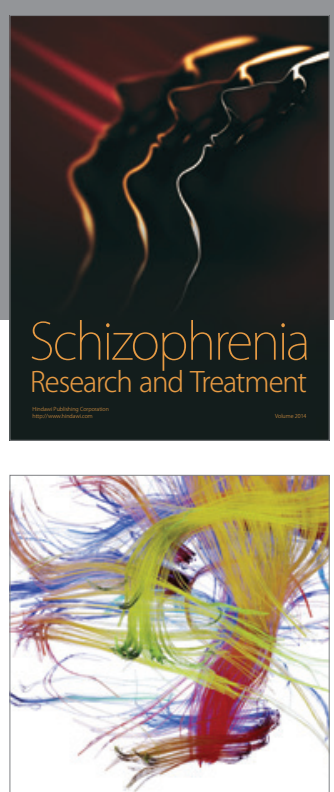

Brain Science

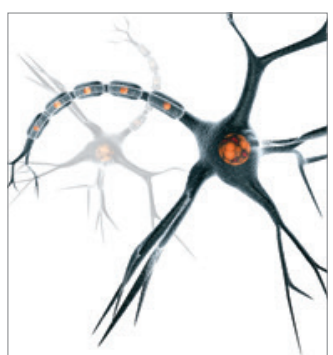

Neural Plasticity
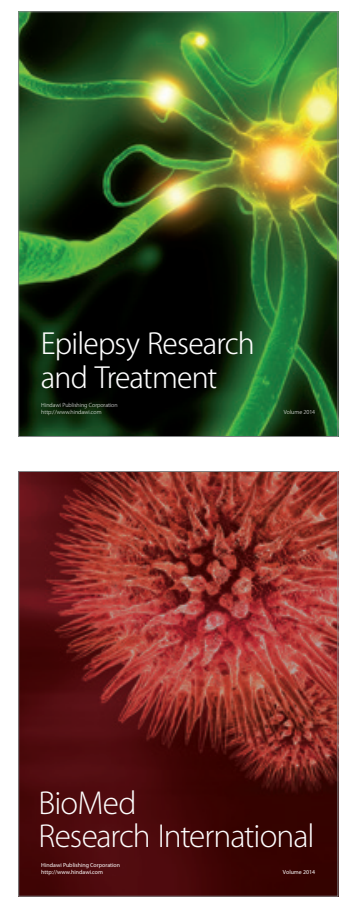

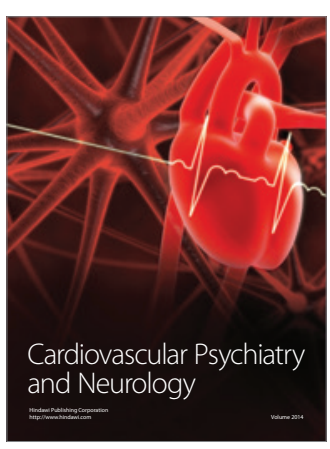

Parkinson's

Disease
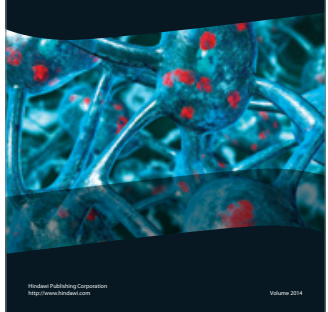